Check for updates

Cite this: RSC Adv., 2017, 7, 21287

Received 15th December 2016 Accepted 31st March 2017

DOI: $10.1039 / c 6 r a 28224 \mathrm{e}$

rsc.li/rsc-advances

\section{Graphene oxide supported titanium dioxide $\&$ ferroferric oxide hybrid, a magnetically separable photocatalyst with enhanced photocatalytic activity for tetracycline hydrochloride degradation}

\begin{abstract}
Wenxia Wang, (DD a Kaijun Xiao, ${ }^{\star a}$ Liang Zhu, ${ }^{a}$ Yurong Yin ${ }^{\star b}$ and Zhaomei Wanga
A facile, robust approach to the synthesis of $\mathrm{Fe}_{3} \mathrm{O}_{4} / \mathrm{rGO} / \mathrm{TiO}_{2}$ nanocomposites is described. The synthesis involves two major steps: (1) preparation of $\mathrm{Fe}_{3} \mathrm{O}_{4} / \mathrm{GO}$ by an electrostatic self-assembly method; (2) deposition of $\mathrm{TiO}_{2}$ on the surface of the $\mathrm{Fe}_{3} \mathrm{O}_{4} / \mathrm{rGO}$ nanocomposite via a hydrothermal method. The asprepared $\mathrm{Fe}_{3} \mathrm{O}_{4} / \mathrm{rGO} / \mathrm{TiO}_{2}$ photocatalyst exhibited an enhanced photocatalytic activity for the degradation of tetracycline hydrochloride $(\mathrm{TC}-\mathrm{HCl})$ over a wide $\mathrm{pH}$ range from 3.0 to 11.0. At optimal conditions, a $92.6 \%$ degradation rate of $\mathrm{TC}-\mathrm{HCl}$ was achieved within $330 \mathrm{~min}$. The enhanced photocatalytic activity could be ascribed to the synergistic effect of the photo-Fenton reaction and electron transportation of graphene. A possible photocatalytic mechanism for $\mathrm{TC}-\mathrm{HCl}$ by the $\mathrm{Fe}_{3} \mathrm{O}_{4} /$ $\mathrm{rGO} / \mathrm{TiO}_{2}$ nanocomposite and $\mathrm{H}_{2} \mathrm{O}_{2}$ was proposed based on the quenching tests and liquid chromatography-mass spectrometry (LC-MS) analysis. Furthermore, a leaching test was also carried out and the result suggested that the leached iron from the reaction system was negligible and the catalyst still exhibited excellent photocatalytic activity after five reaction cycles, which clearly demonstrated that the $\mathrm{Fe}_{3} \mathrm{O}_{4} / \mathrm{rGO} / \mathrm{TiO}_{2}$ nanocomposite was reusable, excellently stable and highly effective.
\end{abstract}

\section{Introduction}

Recently, the widespread use and abuse of antibiotics, like tetracycline hydrochloride (TC-HCl), have aroused particular concern from scientists because of their extensive application to human beings, veterinary medicine, agriculture, aquaculture and planting. ${ }^{1,2}$ As we all know that the excessive use of antibiotics may result in frequent detection of their residues in the environment because of their ineffective biological degradation, ${ }^{3}$ which may lead to untreatable human disease. Besides, it is also a major concern that their persistent exposure to the environment may induce antibiotic-resistant genes. Currently, many methods, such as adsorption, ${ }^{4}$ ion-exchange,${ }^{5}$ microbial degradation, ${ }^{6}$ photocatalytic degradation, ${ }^{7}$ electrolysis ${ }^{8}$ and membrane filtration, ${ }^{9}$ have been investigated for the removal of antibiotics. Among them, photocatalytic degradation was presented as an ideal method due to its high efficiency and low cost. However, the methodology is limited as most of the photocatalysts, such as $\mathrm{TiO}_{2}, \mathrm{SnO}_{2}$ and $\mathrm{ZnO}$, can only respond to $\mathrm{UV}$ irradiation, which accounts for only $4-5 \%$ of solar light. Among the semiconductor catalysts, $\mathrm{TiO}_{2}$ remains one of the most

${ }^{a}$ School of Food Science and Engineering, South China University of Technology, Guangzhou, 510640, China

${ }^{b}$ School of environment and energy, South China University of Technology, Guangzhou, 510640, China. E-mail: fekjxiao@scut.edu.cn; ppyryin@scut.edu.cn; Fax: +86-02087113843; Tel: +86-020-87113843 promising photocatalyst candidates because of its easy availability, high oxidation efficiency, high photostability stability, nanotoxicity, chemical inertness, low cost and environmentally friendly nature. ${ }^{10}$ However, the wide band gap $(\sim 3.2 \mathrm{eV})$ and intrinsic fast recombination of the photoexcited electron-holes of $\mathrm{TiO}_{2}$ are big challenges to achieve higher photocatalytic efficiency and limits the $\mathrm{TiO}_{2}$ application for large scale. ${ }^{11}$ Recent years have witnessed a cornucopia toward the exploration of new $\mathrm{TiO}_{2}$ photocatalyst. Up to now, numerous efforts, such as surface sensitization, ${ }^{12}$ tuning the morphology, ${ }^{13}$ noble metals or metal ions incorporation, ${ }^{\mathbf{1 4}}$ constructing heterojunctions ${ }^{\mathbf{1 5}}$ and transition metals and non-metals doping, ${ }^{16}$ have been made to expand the photoresponse of $\mathrm{TiO}_{2}$ catalyst into solar light and limit the recombination of photogenerated electron-hole pairs. As such, there is still an urgent need to explore a novel approach to remove antibiotics from aqueous solutions efficiently.

Impurities doping of $\mathrm{TiO}_{2}$ (either cations or anions metals) and coupling $\mathrm{TiO}_{2}$ with other semiconductors are the typical approaches to overcome the limitations of pure $\mathrm{TiO}_{2} \cdot{ }^{17}$ Recently, photo-Fenton has received particular concern over the decades for the treatment of wastewater. From this point of view, $\mathrm{TiO}_{2}$ nanoparticle can be introduced into the Fenton system to make a magnetically separable photo-Fenton catalyst with enhanced visible-light driven photocatalytic activity. However, the $\mathrm{Fe}_{3} \mathrm{O}_{4}$ nanoparticles are tend to aggregate and become large particles because of their strong anisotropic 
dipolar interactions, which may affect their dispersibility and specific properties, thus diminishing their activity. ${ }^{18}$ Hence, there is an urgent need to solve the existing problem. Taken together, it is worthwhile to introduce an effective interlayer between $\mathrm{TiO}_{2}$ and $\mathrm{Fe}_{3} \mathrm{O}_{4}$ nanoparticles to maintain their special properties. Graphene has been demonstrated with unique atom-thick 2D structure, superior electron mobility, high specific surface area, excellent transparency, high chemical and electrochemical stability. As such, the graphene is attractive for photocatalyst carrier or promoter. ${ }^{19}$

Herein, we report a two-step process, an electrostatic selfassemble and hydrothermal method, to synthesis of $\mathrm{Fe}_{3} \mathrm{O}_{4}$ / $\mathrm{rGO} / \mathrm{TiO}_{2}$ photocatalyst. The catalytic properties of the asprepared nanocomposite were further investigated in the discoloration and mineralization of TC-HCl in aqueous solution. The important operation variables, including initial solution $\mathrm{pH}$, operation temperature, pollutant concentration and $\mathrm{H}_{2} \mathrm{O}_{2}$ concentration were systematically investigated to find the optimal operation conditions and provide guidance for the practical use of this catalyst. A possible photocatalytic mechanism for TC- $\mathrm{HCl}$ by $\mathrm{Fe}_{3} \mathrm{O}_{4} / \mathrm{rGO} / \mathrm{TiO}_{2}$ nanocomposites and $\mathrm{H}_{2} \mathrm{O}_{2}$ was proposed based on the quenching tests and liquid chromatography-mass spectrometry (LC-MS) analysis.

\section{Experimental section}

\subsection{Materials}

The majority of the chemicals, including ferric chloride hexa-hydrated $\left(\mathrm{FeCl}_{3} \cdot 6 \mathrm{H}_{2} \mathrm{O}\right)$, natural graphite flake, 3aminopropyltrimethoxy-silane (APTMS) and tetrabutyl titanate (TBOT), were purchased from Aladdin Reagent Co., Ltd. (P. R. China), with their purity in analytical grade. The other chemical reagents were analytical grade and directly used as received. The tetracycline hydrochloride ( $\mathrm{TC}-\mathrm{HCl})$ was bought from Aladdin Reagent Co., Ltd. (P. R. China). $\mathrm{H}_{2} \mathrm{SO}_{4}$ and $\mathrm{NaOH}$ solutions were used for $\mathrm{pH}$ adjustment. The structure of the TC- $\mathrm{HCl}$ is illustrated below:

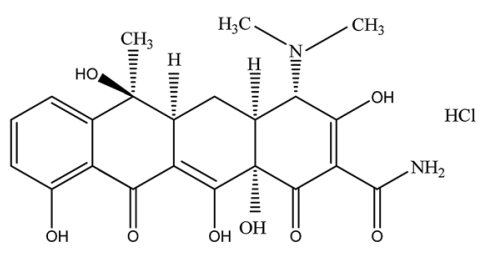

Chemical structure of the tetracycline hydrochloride (TC-HCl)

\subsection{Synthesis of $\mathrm{Fe}_{3} \mathrm{O}_{4}$ nanoparticles}

$\mathrm{Fe}_{3} \mathrm{O}_{4}$ nanoparticles were synthesized on the basis of a procedure reported previously. ${ }^{20}$ In brief, $40 \mathrm{~mL}$ of ethylene glycol containing $\mathrm{FeCl}_{3} \cdot 6 \mathrm{H}_{2} \mathrm{O}$ (1.35 g) was prepared under magnetic stirring. Then, predetermined amount of NaAc (3.6 g) and polyethylene glycol $4000(1.0 \mathrm{~g})$ were quickly added into the premixed clear solution. The mixture was kept stirring for another $30 \mathrm{~min}$ and then transformed in to a $100 \mathrm{~mL}$ Teflon-lined stainless-steel autoclave, heated at $200{ }^{\circ} \mathrm{C}$ for $10 \mathrm{~h}$. Finally, the resultant solution was cooled down to room temperature naturally and then the precipitate was retrieved by centrifugation to give a black powder. The final product was washed three times with ethanol and distilled water and dried at $60^{\circ} \mathrm{C}$ under vacuum.

\subsection{Synthesis of $\mathrm{Fe}_{3} \mathrm{O}_{4} / \mathrm{GO}$ microsphere}

GO was fabricated from natural graphite powder by following a modified Hummers protocol. ${ }^{21}$ The $\mathrm{Fe}_{3} \mathrm{O}_{4} / \mathrm{GO}$ nanocomposites were prepared by a facile electrostatic self-assembly method. Briefly, $1 \mathrm{~g}$ of the $\mathrm{Fe}_{3} \mathrm{O}_{4}$ nanoparticles was sonicated for $1 \mathrm{~h}$ in $140 \mathrm{~mL}$ of isopropyl alcohol solution, and then the above mixture was kept stirring at $80{ }^{\circ} \mathrm{C}$ for $24 \mathrm{~h}$ with the addition of 1 $\mathrm{mL}$ APTMS. After complete reaction, the modified $\mathrm{Fe}_{3} \mathrm{O}_{4}$ microspheres were collected by centrifuged and washed three times by ethanol and distilled water, and then dried at $60{ }^{\circ} \mathrm{C}$ under vacuum. Thereafter, $0.1 \mathrm{~g}$ APTMS modified $\mathrm{Fe}_{3} \mathrm{O}_{4}$ nanoparticle was dissolved into isopropyl alcohol solution and then added dropwise into $150 \mathrm{~mL}$ of aqueous suspension of GO (0.5 $\mathrm{mg} \mathrm{mL}^{-1}$ ) under mechanical stirring. The reaction was allowed to take place at room temperature for $24 \mathrm{~h}$. Finally, the result nanocomposite was washed three times by ethanol and distilled water, and dried at $60{ }^{\circ} \mathrm{C}$ under vacuum.

\subsection{Fabrication of $\mathrm{Fe}_{3} \mathrm{O}_{4} / \mathrm{rGO} / \mathrm{TiO}_{2}$ nanocomposite}

$\mathrm{Fe}_{3} \mathrm{O}_{4} / \mathrm{rGO} / \mathrm{TiO}_{2}$ nanocomposite was synthesized by a facile hydrothermal method using $\mathrm{Fe}_{3} \mathrm{O}_{4} / \mathrm{GO}$ microsphere and tetrabutyl titanate (TBOT) as raw materials. In a typical synthesis, 30 $\mathrm{mL}$ of $\mathrm{Fe}_{3} \mathrm{O}_{4} / \mathrm{GO}$ microsphere was dissolved in $25 \mathrm{~mL}$ isopropyl alcohol and the resulting solution was obtained after ultrasonic for $30 \mathrm{~min}$. Then $100 \mu \mathrm{L}$ tetrabutyl titanate (ТВOT) was added dropwise to the above solution under continuous mechanical stirring and kept stirring for $1 \mathrm{~h}$. Afterward, $1 \mathrm{~mL}$ distilled water was added dropwise under mechanical stirring. The mixture was stirring for another $1 \mathrm{~h}$ before the mixture was transferred into a $100 \mathrm{~mL}$ Teflon-lined stainless steel autoclave for hydrothermal treatment at $180{ }^{\circ} \mathrm{C}$ for $8 \mathrm{~h}$. After the autoclave cooled down to room temperature naturally, the final product was washed three times by absolute ethanol and distilled water, dried at $60{ }^{\circ} \mathrm{C}$ under vacuum.

\subsection{Characterization method}

The morphology and structure of $\mathrm{Fe}_{3} \mathrm{O}_{4} / \mathrm{rGO} / \mathrm{TiO}_{2}$ nanocomposite were characterized by transmission electron microscopy (TEM, Tecnai F20, $200 \mathrm{kV}$ ). The SEM images and EDS mapping was taken by the scanning electron microscopy (SEM, JSM 6701F). The zeta potential measurement was performed by using a Malvern zetasizer (Zetasizer 2000). The crystallographic and chemical bond analysis of the prepared materials were acquired by the X-ray diffractometry (Rigaku Miniflex XRD, Bruker) and Fourier transforms infrared spectroscopy (FTIR, VERTEX 33, Bruker). The X-ray photoelectron spectroscopy (XPS) (Kratos Axis Ultra DLD) of the catalyst was obtained from an axis-ultra X-ray photoelectron spectrometer with monochromatized Al-K $\alpha$ radiation. The $\mathrm{N}_{2}$ adsorptiondesorption isotherms were recorded using the accelerated 
surface area porosimetry system (ASAP 2020, Micromeritics). The vibrating sample magnetometry (VSM, LAKESHORE-7304) was used to assess the magnetic property at room temperature. Raman spectroscopy (LabRAM Aramis, Germany) was carried out on the samples at room temperature using a $785 \mathrm{~nm}$ Nd-YAG laser excitation source.

\subsection{Photocatalytic degradation of tetracycline hydrochloride (TC-HCl)}

Visible light-driven photocatalytic activity of each sample was measured in terms of the degradation of tetracycline hydrochloride (TC-HCl, $20 \mathrm{mg} \mathrm{L}^{-1}$ ). In a typical experiment, a predetermined amount of $\mathrm{Fe}_{3} \mathrm{O}_{4} / \mathrm{rGO} / \mathrm{TiO}_{2}$ nanocomposite was suspended in $50 \mathrm{~mL}$ of TC-HCl solution $\left(20 \sim 120 \mathrm{mg} \mathrm{L}^{-1}\right)$. The suspension was kept stirring for $30 \mathrm{~min}$ in darkness to reach adsorption-desorption equilibrium. Then the suspension was irradiated with a $150 \mathrm{~W}$ Xenon lamp which was located with a distance of $10 \mathrm{~cm}$ at side of the reaction solution. At the predetermined time intervals, the analytical samples were withdrawn from the solution and immediately centrifuged at $8000 \mathrm{rpm}$ for $1 \mathrm{~min}$, then analysed using a spectrophotometer (UV-1801) at $356 \mathrm{~nm}$.

In order to detect the active species during the photocatalytic reaction, benzoquinone (BQ), dimethylsulfoxide (DMSO), triethanolamine (TEOA), and isopropanol (IPA) were added into the TC-HCl suspension solution containing the $50 \% \mathrm{Fe}_{3} \mathrm{O}_{4} / \mathrm{rGO} /$ $\mathrm{TiO}_{2}$ composites photocatalyst to trap superoxide radicals $\left({ }^{\circ} \mathrm{O}_{2}{ }^{-}\right), \mathrm{e}^{-}$, holes $\left(\mathrm{h}^{+}\right)$, and hydroxyl radicals ( $\left.{ }^{\circ} \mathrm{OH}\right)$, respectively.

\section{Results and discussion}

\subsection{Structural identification}

The morphology of as-prepared $\mathrm{Fe}_{3} \mathrm{O}_{4}, \mathrm{Fe}_{3} \mathrm{O}_{4} / \mathrm{GO}$ and $\mathrm{Fe}_{3} \mathrm{O}_{4} /$ $\mathrm{rGO} / \mathrm{TiO}_{2}$ was observed using SEM and TEM (Fig. 1). From Fig. 1a, we can see the spherical and uniform $\mathrm{Fe}_{3} \mathrm{O}_{4}$ microspheres and they all had very narrow diameter distributions, which can be more clearly seen at the TEM image illustrated in Fig. 1d. After assembly with GO nanosheets, the surface of the resulting binary nanoparticle became corrugated, which can be further conformed by the TEM image (Fig. 1e). This result indicated that there do exist thin layer on the surface of $\mathrm{Fe}_{3} \mathrm{O}_{4}$ particles due to the successfully integrating with GO. And the size of the binary nanoparticle of $\mathrm{Fe}_{3} \mathrm{O}_{4} / \mathrm{GO}$ became larger compared to that of the bare $\mathrm{Fe}_{3} \mathrm{O}_{4}$ particles. Shown in Fig. 1c, the as-prepared $\mathrm{Fe}_{3} \mathrm{O}_{4} / \mathrm{rGO} / \mathrm{TiO}_{2}$ nanocomposite reveal the likesphere morphology in terms of size. The low-resolution TEM image in Fig. 1f further exhibit that the presence of uniform $\mathrm{Fe}_{3} \mathrm{O}_{4} / \mathrm{rGO} / \mathrm{TiO}_{2}$ nanocomposite resembling tiny rose petals around the like-sphere morphology, which may be attributed to the asymmetric deposition of the $\mathrm{TiO}_{2}$ nanoparticles on the surface of the $\mathrm{Fe}_{3} \mathrm{O}_{4} / \mathrm{GO}$ microsphere induced by the slow kinetics associated with both reduction and surface diffusion. ${ }^{22}$ The high-resolution TEM (HRTEM) image of the $\mathrm{Fe}_{3} \mathrm{O}_{4} / \mathrm{rGO} /$ $\mathrm{TiO}_{2}$ nanocomposite is shown in Fig. 1g. There are two interplanar spacings $(d=0.230$ and $0.290 \mathrm{~nm})$ corresponding to (004) planes of anatase $\mathrm{TiO}_{2}$ and (220) plane of $\mathrm{Fe}_{3} \mathrm{O}_{4}$, respectively. ${ }^{23}$ The related SAED pattern in Fig. $1 \mathrm{~h}$ suggests the high crystallinity of $\mathrm{TiO}_{2}$ nanoparticles. The positional distribution of $\mathrm{Fe}$ and $\mathrm{Ti}$ in the $\mathrm{Fe}_{3} \mathrm{O}_{4} / \mathrm{rGO} / \mathrm{TiO}_{2}$ nanocomposite was revealed by high-angle annular dark-field scanning TEM (HAADF-TEM) and EDX elemental mapping patterns. The HAADF-STEM image shows the different luminance in the signal $\mathrm{Fe}_{3} \mathrm{O}_{4} / \mathrm{rGO} / \mathrm{TiO}_{2}$ nanoparticle (Fig. 1i), manifesting that the $\mathrm{Fe}_{3} \mathrm{O}_{4} / \mathrm{rGO} / \mathrm{TiO}_{2}$ nanocomposites have a core-shell structure rather than an alloy structure..$^{24,25}$

To gain insight into the crystal structure of the as-prepared samples, X-ray diffraction patterns of $\mathrm{Fe}_{3} \mathrm{O}_{4}$, anatase $\mathrm{TiO}_{2}$, $\mathrm{Fe}_{3} \mathrm{O}_{4} / \mathrm{TiO}_{2}$ and $\mathrm{Fe}_{3} \mathrm{O}_{4} / \mathrm{rGO} / \mathrm{TiO}_{2}$ were measured. Fig. 2a illustrated XRD pattern of the $\mathrm{Fe}_{3} \mathrm{O}_{4}$, the six characteristic peaks located at $18.25^{\circ}, 29.98^{\circ}, 36.37^{\circ}, 43.47^{\circ}, 53.77^{\circ}, 57.28^{\circ}$ and $63.14^{\circ}$ are indexed to (111), (220), (311), (400), (422), (511) and (440), respectively. The results agree well with the typical structure of $\mathrm{Fe}_{3} \mathrm{O}_{4}$ nanoparticles [JCPDS: 19-0629]. ${ }^{26}$ Typical sharp and intense peaks observed in Fig. $2 \mathrm{~b}$ can be attributed to the anatase phase of $\mathrm{TiO}_{2}$ (JCPDS 21-1272). In fact, similar result is also reported in the former literature. ${ }^{27}$ The XRD pattern of the $\mathrm{Fe}_{3} \mathrm{O}_{4} / \mathrm{TiO}_{2}$ and $\mathrm{Fe}_{3} \mathrm{O}_{4} / \mathrm{rGO} / \mathrm{TiO}_{2}$ shown in Fig. 2a match both the $\mathrm{Fe}_{3} \mathrm{O}_{4}$ nanoparticles and the anatase $\mathrm{TiO}_{2}$, which conformed that the $\mathrm{TiO}_{2}$ nanoparticles were successfully installed on the surface of the $\mathrm{Fe}_{3} \mathrm{O}_{4}$ nanospheres and $\mathrm{Fe}_{3} \mathrm{O}_{4} / \mathrm{GO}$ composites. ${ }^{28}$ The FTIR spectra of anatase $\mathrm{TiO}_{2}, \mathrm{Fe}_{3} \mathrm{O}_{4}, \mathrm{Fe}_{3} \mathrm{O}_{4} /$ $\mathrm{TiO}_{2}$ and $\mathrm{Fe}_{3} \mathrm{O}_{4} / \mathrm{rGO} / \mathrm{TiO}_{2}$ are recorded in Fig. 2b. For anatase $\mathrm{TiO}_{2}$ (Fig. 2b), the peak located at $583 \mathrm{~cm}^{-1}$ is attributed to stretching vibration of Ti-O-Ti bond, which is consistent with previous literature. ${ }^{29}$ As can be seen from Fig. $2 \mathrm{~b}$, the strong absorption peak at $582 \mathrm{~cm}^{-1}$ correspond to the $\mathrm{Fe}-\mathrm{O}$ stretching vibration of $\mathrm{Fe}_{3} \mathrm{O}_{4}$. Meanwhile, in comparison with $\mathrm{Fe}_{3} \mathrm{O}_{4} / \mathrm{TiO}_{2}$, the peaks at $1258 \mathrm{~cm}^{-1}$ and $1073 \mathrm{~cm}^{-1}$ can be attributed to $\mathrm{C}-\mathrm{O}$ in $\mathrm{COH} / \mathrm{COC}$ of the $\mathrm{GO}$, which indicates that the $\mathrm{GO}$ was not completely reduced.

The magnetic properties of the as-obtained materials were characterized by a vibrating sample magnetometer at room temperature. As illustrated in Fig. 3a, the saturation magnetization values of $\mathrm{Fe}_{3} \mathrm{O}_{4} \mathrm{NPs}, \mathrm{Fe}_{3} \mathrm{O}_{4} / \mathrm{GO}$ and $\mathrm{Fe}_{3} \mathrm{O}_{4} / \mathrm{rGO} / \mathrm{TiO}_{2}$ nanocomposite are 215.0, 50.84 and $20.0 \mathrm{emu} \mathrm{g}^{-1}$, respectively. It is worth noting that the saturation magnetization value of the nanocomposites decreased sharply after coating with the $\mathrm{TiO}_{2}$ or GO sheet, which are the non-magnetic nanocomposites content in the hybrids that reduce the magnetization. ${ }^{26}$ However, the $\mathrm{Fe}_{3} \mathrm{O}_{4} / \mathrm{rGO} / \mathrm{TiO}_{2}$ still exhibited good magnetic properties that can ensure them be easily collected and recycled from aqueous solution by simply putting an external magnetic field. The inset of Fig. 3a shows the attraction of the $\mathrm{Fe}_{3} \mathrm{O}_{4} / \mathrm{rGO} / \mathrm{TiO}_{2}$ nanoparticles to a commercial magnet in $1 \mathrm{~min}$. The nanoparticles homogeneously dispersed in liquid could be easily collected by an external magnetic field, which conformed their excellent superparamagnetic property. Fig. $3 \mathrm{~b}$ shows the UV-vis absorbance of $\mathrm{GO}$ and $\mathrm{Fe}_{3} \mathrm{O}_{4} / \mathrm{rGO} / \mathrm{TiO}_{2}$. It is evident that the UV absorption peak of the $\mathrm{GO}$ and $\mathrm{Fe}_{3} \mathrm{O}_{4} / \mathrm{rGO} / \mathrm{TiO}_{2}$ appears at $227 \mathrm{~nm}$ and $257 \mathrm{~nm}$, respectively. The red-shift may be caused by the formation of chemical bond between $\mathrm{GO}$ and $\mathrm{Fe}_{3} \mathrm{O}_{4} \cdot{ }^{30}$

Raman spectroscopy was used to fully understand the structure and crystalline phase of the $\mathrm{Fe}_{3} \mathrm{O}_{4} / \mathrm{rGO} / \mathrm{TiO}_{2}$ 

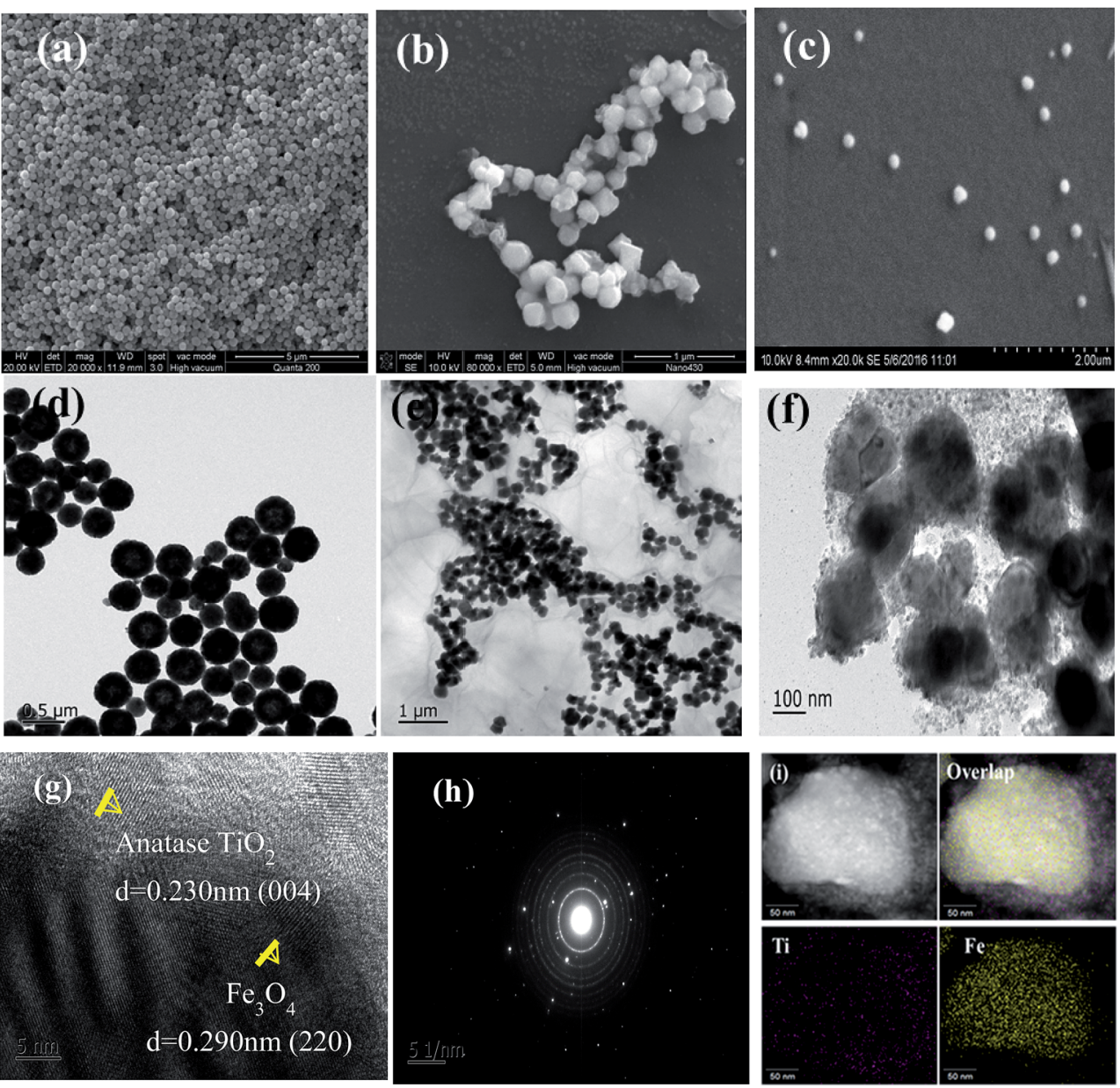

Fig. 1 Typical SEM image (a-c) and TEM (d-f) image of $\mathrm{Fe}_{3} \mathrm{O}_{4}, \mathrm{Fe}_{3} \mathrm{O}_{4} / \mathrm{GO}, \mathrm{Fe}_{3} \mathrm{O}_{4} / \mathrm{rGO} / \mathrm{TiO}_{2}$ nanocomposite (g) $\mathrm{HRTEM}$ image of Fe $3 \mathrm{O}_{4} / \mathrm{rGO} /$ $\mathrm{TiO}_{2}$ nanoparticles, (h) selected area electron diffraction pattern (SAED) pattern of $\mathrm{Fe}_{3} \mathrm{O}_{4} / \mathrm{rGO} / \mathrm{TiO} \mathrm{O}_{2}$ nanocomposite (i) HAADF-STEM image of the individual $\mathrm{Fe}_{3} \mathrm{O}_{4} / \mathrm{rGO} / \mathrm{TiO}_{2}$ nanoparticle and the corresponding elemental mapping images of $\mathrm{Fe}_{3} \mathrm{O}_{4} / \mathrm{rGO}^{\mathrm{TiO}} \mathrm{T}_{2}$ nanocomposite.

nanocomposite. It is obvious from Fig. 4a that the $\mathrm{Fe}_{3} \mathrm{O}_{4} / \mathrm{rGO} /$ $\mathrm{TiO}_{2}$ hybrids show the typical Raman peaks of $\mathrm{Fe}_{3} \mathrm{O}_{4} / \mathrm{TiO}_{2}$ and $\mathrm{Fe}_{3} \mathrm{O}_{4} / \mathrm{GO}$. Besides, the value of $I_{\mathrm{D}} / I_{\mathrm{G}}$ for $\mathrm{Fe}_{3} \mathrm{O}_{4} / \mathrm{rGO} / \mathrm{TiO}_{2}$ hybrids $\left(I_{\mathrm{D}} / I_{\mathrm{G}}=1.18\right)$ is higher than for pure $\mathrm{Fe}_{3} \mathrm{O}_{4} / \mathrm{GO}\left(I_{\mathrm{D}} / I_{\mathrm{G}}=\right.$ 0.89 ), which indicates the successful transformation of GO to $\mathrm{r}-$
GO through hydrothermal. ${ }^{31}$ Taking a detailed look at the Raman spectra of $\mathrm{TiO}_{2}$ and $\mathrm{Fe}_{3} \mathrm{O}_{4} / \mathrm{TiO}_{2}$ (Fig. 4b), it is clear that the Raman peaks appear at $142,195,395,516$, and $639 \mathrm{~cm}^{-1}$ are ascribed to vibration modes of $E_{\mathrm{g}(1)}, E_{\mathrm{g}}, B_{1 \mathrm{~g}}, A_{1 \mathrm{~g}}+B_{1 \mathrm{~g}}$, and $E_{\mathrm{g}(2)}$, respectively. ${ }^{32,33}$ The result is consistent with the XRD analysis.
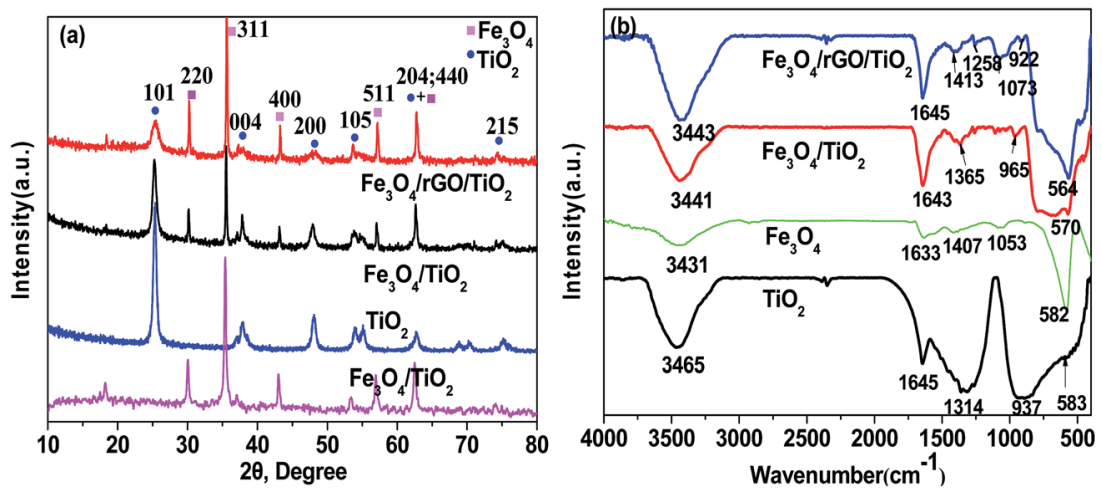

Fig. 2 XRD patterns (a) and FTIR spectra (b) of $\mathrm{Fe}_{3} \mathrm{O}_{4}$, anatase $\mathrm{TiO}_{2}, \mathrm{Fe}_{3} \mathrm{O}_{4} / \mathrm{TiO}_{2}$ and $\mathrm{Fe}_{3} \mathrm{O}_{4} / \mathrm{rGO} / \mathrm{TiO}$. The blue spheres (•) and pink cubes ( $($ ) indicate the typical diffraction peaks of anatase $\mathrm{TiO}_{2}$ and $\mathrm{Fe}_{3} \mathrm{O}_{4}$, respectively. 

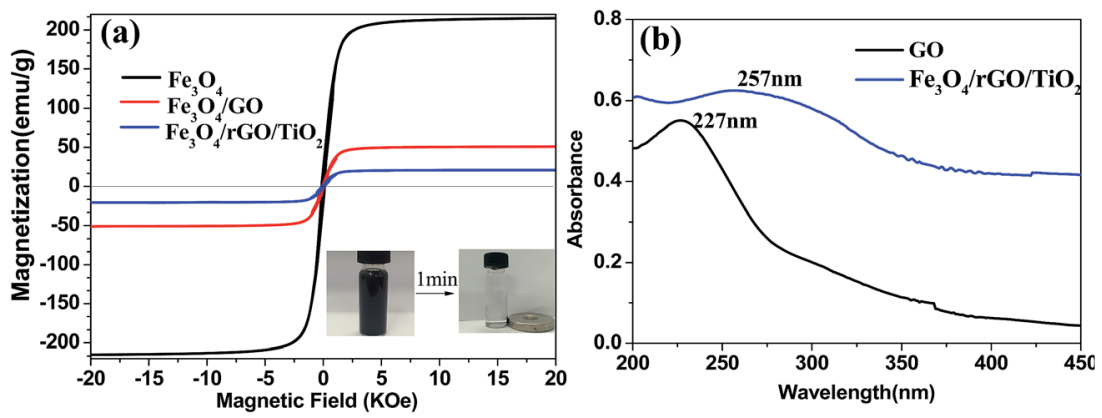

Fig. 3 (a) Magnetic hysteresis curves of $\mathrm{Fe}_{3} \mathrm{O}_{4}$ nanoparticles, $\mathrm{Fe}_{3} \mathrm{O}_{4} / \mathrm{GO}$ and $\mathrm{Fe}_{3} \mathrm{O}_{4} / \mathrm{rGO} / \mathrm{TiO}_{2}$ nanocomposite (inset: separation of particles dispersed in water by a magnet in $1 \mathrm{~min}$ ). (b) UV-vis absorbance of $\mathrm{GO}$ and $\mathrm{Fe}_{3} \mathrm{O}_{4} / \mathrm{rGO} / \mathrm{TiO}_{2}$ nanocomposite.
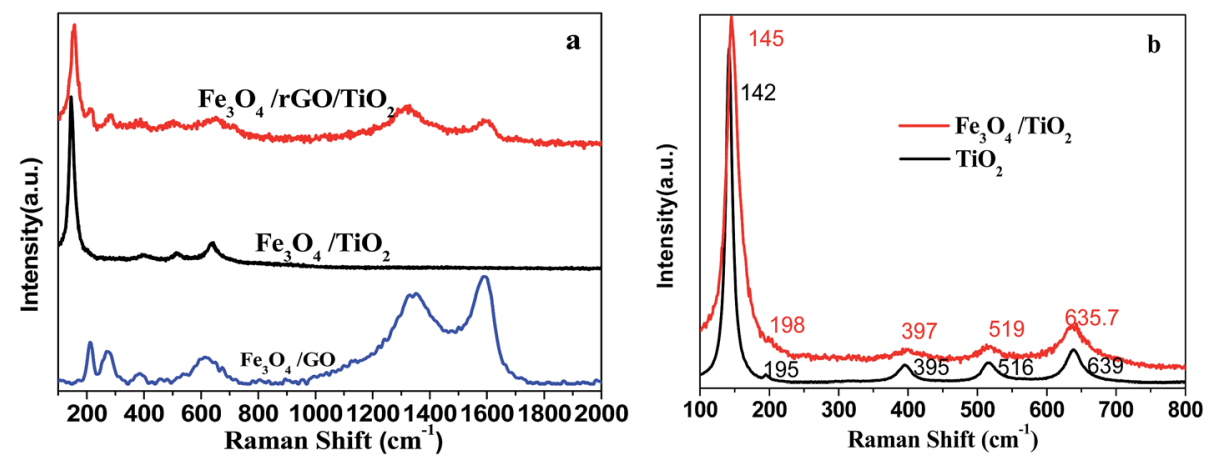

Fig. 4 Raman spectra of (a) $\mathrm{Fe}_{3} \mathrm{O}_{4} / \mathrm{TiO}_{2}, \mathrm{Fe}_{3} \mathrm{O}_{4} / \mathrm{GO}, \mathrm{Fe}_{3} \mathrm{O}_{4} / \mathrm{rGO} / \mathrm{TiO}_{2}$ nanocomposite (b) detail information of the Raman spectra of TiO ${ }_{2}$ and $\mathrm{Fe}_{3} \mathrm{O}_{4} / \mathrm{TiO}_{2}$ nanocomposite.

The specific surface areas of $\mathrm{Fe}_{3} \mathrm{O}_{4} / \mathrm{GO}$ and $\mathrm{Fe}_{3} \mathrm{O}_{4} / \mathrm{rGO} / \mathrm{TiO}_{2}$ hybrids were compared using Nitrogen adsorption-desorption measurements (Fig. 5). It is evident that $\mathrm{Fe}_{3} \mathrm{O}_{4} / \mathrm{rGO} / \mathrm{TiO}_{2}$ has similar isotherm to that of $\mathrm{Fe}_{3} \mathrm{O}_{4} / \mathrm{GO}$, exhibiting type IV isotherms in IUPAC classification with a H1-type hysteresis loop, which conformed the mesostructures of the as-prepared materials. ${ }^{3}$ Besides, the adsorption quantity of $\mathrm{Fe}_{3} \mathrm{O}_{4} / \mathrm{rGO} /$ $\mathrm{TiO}_{2}$ increased remarkably compared to that of the $\mathrm{Fe}_{3} \mathrm{O}_{4} / \mathrm{GO}$, which demonstrate the synergistic effect of the $\mathrm{TiO}_{2}, \mathrm{GO}$ and $\mathrm{Fe}_{3} \mathrm{O}_{4}$. Based on the isotherms, the BET surface areas of the

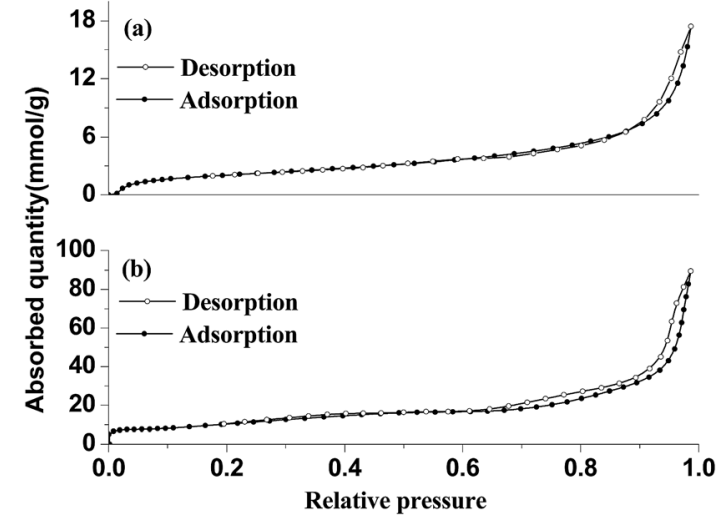

Fig. $5 \mathrm{~N}_{2}$ adsorption-desorption isotherms of (a) $\mathrm{Fe}_{3} \mathrm{O}_{4} / \mathrm{GO}$ (b) $\mathrm{Fe}_{3} \mathrm{O}_{4} / \mathrm{rGO} / \mathrm{TiO}_{2}$ nanocomposite.
$\mathrm{Fe}_{3} \mathrm{O}_{4} / \mathrm{GO}$ and $\mathrm{Fe}_{3} \mathrm{O}_{4} / \mathrm{rGO} / \mathrm{TiO}_{2}$ were determined to be 6.08 and $33.47 \mathrm{~m}^{2} \mathrm{~g}^{-1}$, respectively. The average pore sizes of $\mathrm{Fe}_{3} \mathrm{O}_{4} / \mathrm{GO}$ and $\mathrm{Fe}_{3} \mathrm{O}_{4} / \mathrm{rGO} / \mathrm{TiO}_{2}$ composites are 18.29 and $11.48 \mathrm{~nm}$, respectively.

In order to further confirm the chemical status and elemental composite of the as-prepared $\mathrm{Fe}_{3} \mathrm{O}_{4} / \mathrm{TiO}_{2}$ and $\mathrm{Fe}_{3} \mathrm{O}_{4} /$ $\mathrm{rGO} / \mathrm{TiO}_{2}$ nanomaterials, the XPS measurement was carried out. As apparent from Fig. 6, in the full XPS spectra of the samples, the presence of Fe 2p1, Fe 2p3, O 1s, Ti 2p, and C 1s can be ascertained. In Fig. $6 \mathrm{~b}$, the Ti $2 \mathrm{p}$ core levels can be deconvoluted to a doublet ( $\mathrm{Ti} 2 \mathrm{p}_{3 / 2}$ and $\mathrm{Ti} 2 \mathrm{p}_{1 / 2}$ ). However, the binding energy increased compared to the former literatures. ${ }^{34,35}$ It may be caused by the interaction between Ti and the oxide functional groups of rGO, since the electronegativity of oxygen is higher than that of carbon. As for the $\mathrm{C} 1 \mathrm{~s}$ peaks depicted in Fig. 6c, the C 1s peaks of $\mathrm{Fe}_{3} \mathrm{O}_{4} / \mathrm{TiO}_{2}$ and $\mathrm{Fe}_{3} \mathrm{O}_{4} / \mathrm{rGO} / \mathrm{TiO}_{2}$ could be fitted by three peaks, which belong to the following functional groups: $\mathrm{C}=\mathrm{O}(284.8 \mathrm{eV}), \mathrm{C}-\mathrm{O}-\mathrm{C}(286.9 \mathrm{eV})$ and $\mathrm{O}-\mathrm{C}=\mathrm{O}(288.7 \mathrm{eV}) . \mathrm{In}$ Fig. 6d, the intensity peaks located at $710.8 \mathrm{eV}$ and $724.8 \mathrm{eV}$ belong to $\mathrm{Fe} 2 \mathrm{p}_{3 / 2}$ and $\mathrm{Fe} 2 \mathrm{p}_{1 / 2}$ respectively, implying the successful synthesis of $\mathrm{Fe}_{3} \mathrm{O}_{4}$ (ref. 36).

\subsection{Photocatalytic performance}

3.2.1 Photocatalytic activity of $\mathrm{Fe}_{3} \mathrm{O}_{4} / \mathrm{rGO} / \mathrm{TiO}_{2}$ nanocomposite. It has been widely accepted that the initial $\mathrm{pH}$ level of reaction system plays a key role in the degradation activity of 

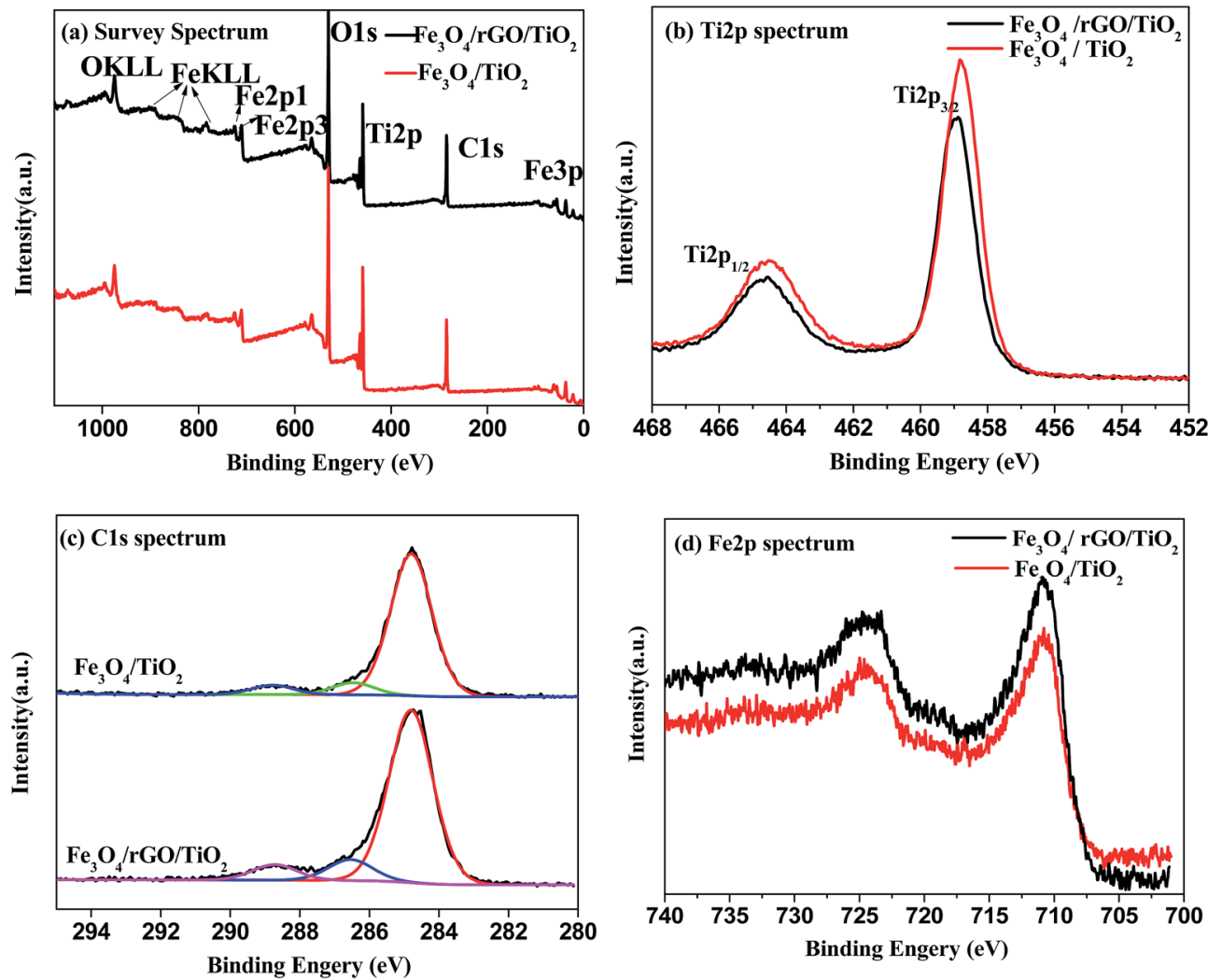

Fig. 6 XPS spectra of $\mathrm{Fe}_{3} \mathrm{O}_{4} / \mathrm{TiO}_{2}$ and $\mathrm{Fe}_{3} \mathrm{O}_{4} / \mathrm{rGO} / \mathrm{TiO}_{2}$ nanocomposite: (a) full spectra of samples; (b) Ti $2 \mathrm{p}$ peaks; (c) $\mathrm{C} 1 \mathrm{~s}$ peaks; (d) $\mathrm{Fe} 2 \mathrm{p}$ peaks.

catalyst toward TC-HCl. ${ }^{37,38}$ In this study, the effect of initial $\mathrm{pH}$ value, ranging from 3 to 11, on the degradation rate of TC-HCl was investigated. The initial $\mathrm{pH}$ of pollutant solution was changed by adding $1 \mathrm{M} \mathrm{H}_{2} \mathrm{SO}_{4}$ or $\mathrm{NaOH}$. As presented in Fig. 7a, the initial $\mathrm{pH}$ has a certain impact on TC-HCl removal. The degradation rate was achieved at $92.6 \%$ under $\mathrm{pH} 3$. According to the $\mathrm{p} K_{\mathrm{a}}$ values of the $\mathrm{TC}-\mathrm{HCl}$, the TC- $\mathrm{HCl}$ mainly exists as cation $\left(\mathrm{TC}^{3+}\right)$ when the $\mathrm{pH}<3.3$. Meanwhile, the zeta potential of $\mathrm{Fe}_{3} \mathrm{O}_{4} / \mathrm{rGO} / \mathrm{TiO}_{2}$ was negative. The electrostatic interactions between the catalyst and the TC-HCl was much stronger, thus enhancing the degradation rate. However, the degradation rate decreased slightly with the increasing initial $\mathrm{pH}$ values of the solutions from 5-11, under which condition the molecular structure of the TC-HCl presence as the form of $\mathrm{TCH}^{2 \pm}, \mathrm{TCH}^{-}$, $\mathrm{TC}^{2-}$ rather than sole negative or positive particle. Besides, the release of $\mathrm{OH}$ from the reaction system also has a close connection with the $\mathrm{pH}$ values. It is well known that the acidic environment is much more favorable for the produce of ${ }^{\circ} \mathrm{OH}$ from the reaction system, especially for the homogeneous Fenton system. Such a severe environment limits the application of the Fenton catalyst, and the as-prepared catalyst shows a high degradation rate under the neutral or alkaline environment, which can overcome the disadvantage of the homogeneous catalysis.

Fig. 7b illustrate the TC-HCl removal with various initial TC$\mathrm{HCl}$ concentrations. It is obvious that the degradation rate of $\mathrm{TC}-\mathrm{HCl}$ was related to the pollutant concentration, and the lower initial TC-HCl concentration in aqueous solution with the predetermined dosage of $\mathrm{Fe}_{3} \mathrm{O}_{4} / \mathrm{rGO} / \mathrm{TiO}_{2}$ and $\mathrm{H}_{2} \mathrm{O}_{2}$ favor the TC-HCl removal. The TC-HCl degradation rate decreased from $92.6 \%$ to $41.4 \%$ as the initial $\mathrm{TC}-\mathrm{HCl}$ concentration increased from 20.0 to $120.0 \mathrm{mg} \mathrm{L}^{-1}$. This can be attribute to the following reasons: the fixed amount of $\mathrm{Fe}_{3} \mathrm{O}_{4} / \mathrm{rGO} / \mathrm{TiO}_{2}$ and $\mathrm{H}_{2} \mathrm{O}_{2}$ produce the fixed ' $\mathrm{OH}$ amount, and the amount of TC- $\mathrm{HCl}$ molecules per unit volume increased with the increase of the TC-HCl concentration, leading to the decrease in the percentage of TC-HCl molecule involved into the reaction and the lower degradation rate.

The initial $\mathrm{H}_{2} \mathrm{O}_{2}$ also has a decisive effect on the degradation of the TC-HCl. As presented in Fig. 7c, TC-HCl removal reaches only $20 \%$ in the presence of $\mathrm{Fe}_{3} \mathrm{O}_{4} / \mathrm{rGO} / \mathrm{TiO}_{2}$ nanocomposite without any oxidant $\mathrm{H}_{2} \mathrm{O}_{2}$, which was attributed to the adsorption of TC-HCl molecules on $\mathrm{Fe}_{3} \mathrm{O}_{4} / \mathrm{rGO} / \mathrm{TiO}_{2}$ nanocomposite. The introduction of $\mathrm{H}_{2} \mathrm{O}_{2}$ into the TC-HCl solutions significantly accelerated the degradation of TC- $\mathrm{HCl}$ and the degradation performance was dependent on the initial $\mathrm{H}_{2} \mathrm{O}_{2}$ concentration in the pollutant solution. The degradation rate of TC-HCl increased when the $\mathrm{H}_{2} \mathrm{O}_{2}$ concentration increased from $20 \mathrm{mmol} \mathrm{L}^{-1}$ to $40 \mathrm{mmol} \mathrm{L}^{-1}$, but decreased with further increasing $\mathrm{H}_{2} \mathrm{O}_{2}$ concentration to $60 \mathrm{mmol} \mathrm{L}^{-1}$ and $80 \mathrm{mmol}$ $\mathrm{L}^{-1}$. It is known that for the heterogeneous Fenton reaction the highly hydroxyl radicals, hence higher TC-HCl removal, are available at higher initial $\mathrm{H}_{2} \mathrm{O}_{2}$ concentrations. Nevertheless, $\mathrm{H}_{2} \mathrm{O}_{2}$ can also act as a hydroxyl radical scavenger as described in eqn (1) and (2), and can also take place the self-decomposition as described in eqn (3), so the further increase of the $\mathrm{H}_{2} \mathrm{O}_{2}$ 
(a)

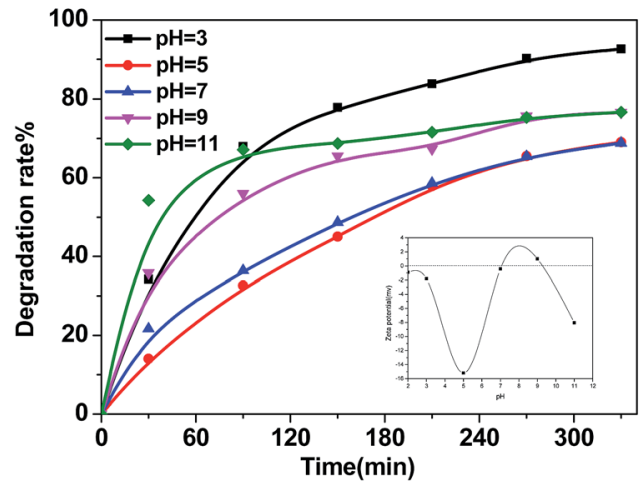

(c)

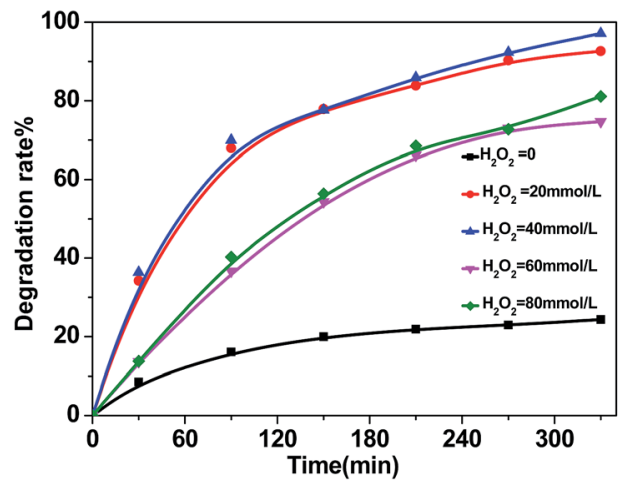

(b)

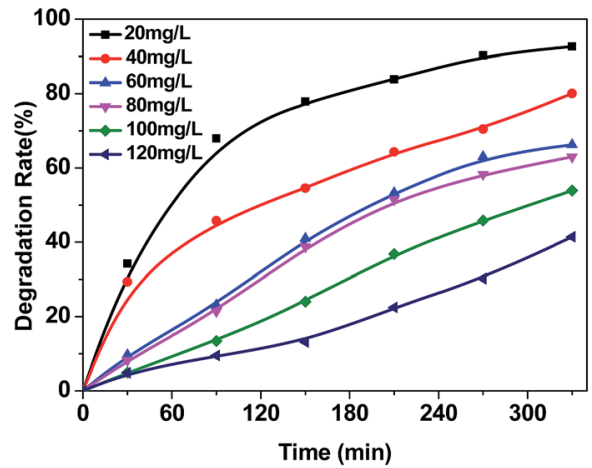

(d)

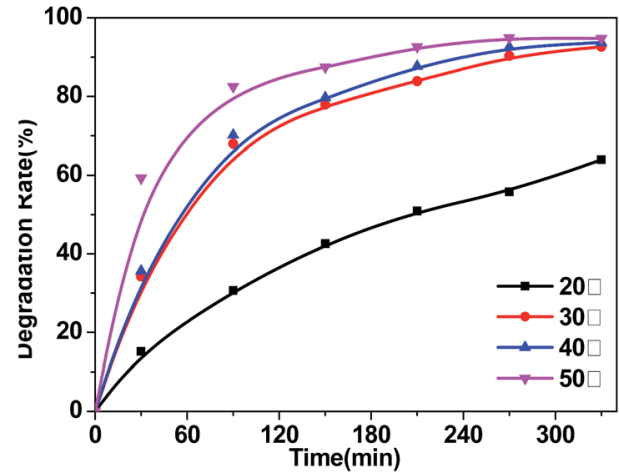

Fig. 7 Effects of (a) initial $\mathrm{pH}$ (inset: Zeta potential analysis of the $\mathrm{Fe}_{3} \mathrm{O}_{4} / \mathrm{rGO} / \mathrm{TiO}$, nanocomposite at different pH), (b) pollutant concentration, (c) $\mathrm{H}_{2} \mathrm{O}_{2}$ concentration and (d) temperature in degradation rates of $\mathrm{TC}-\mathrm{HCl}$. Experimental conditions: (a) catalyst loading $=400 \mathrm{mg} \mathrm{L}{ }^{-1}$; initial TC$\mathrm{HCl}$ concentration $=20 \mathrm{mg} \mathrm{L}{ }^{-1} ; \mathrm{H}_{2} \mathrm{O}_{2}$ concentration $=20 \mathrm{mmol} \mathrm{L}^{-1}$; temperature $=30 \pm 1{ }^{\circ} \mathrm{C}$; (b) catalyst loading $=400 \mathrm{mg} \mathrm{L}^{-1}$; $\mathrm{H}_{2} \mathrm{O}_{2}$ concentration $=20 \mathrm{mmol} \mathrm{L}^{-1}$; temperature $=30 \pm 1{ }^{\circ} \mathrm{C}$; initial $\mathrm{pH}=3$; (c) catalyst loading $=400 \mathrm{mg} \mathrm{L}^{-1}$; initial TC-HCl concentration $=$ $20 \mathrm{mg} \mathrm{L}^{-1}$; temperature $=30 \pm 1^{\circ} \mathrm{C} ; \mathrm{pH}=3$; (d) catalyst loading $=400 \mathrm{mg} \mathrm{L}^{-1}$; initial $\mathrm{TC}$ concentration $=20 \mathrm{mg} \mathrm{L}^{-1}$; $\mathrm{H}_{2} \mathrm{O}_{2}$ concentration $=$ $20 \mathrm{mmol} \mathrm{L}^{-1} ; \mathrm{pH}=3$.

concentration cannot result in the significant increase of hydroxyl radicals and the enhancement of the $\mathrm{TC}-\mathrm{HCl}$ removal. $^{39}$

$$
\begin{gathered}
\mathrm{HO}^{\bullet}+\mathrm{H}_{2} \mathrm{O}_{2} \rightarrow \mathrm{H}_{2} \mathrm{O}+\mathrm{HO}_{2} \\
\mathrm{HO}^{\bullet}+\mathrm{HO}_{2} \cdot \rightarrow \mathrm{H}_{2} \mathrm{O}+\mathrm{O}_{2} \\
2 \mathrm{H}_{2} \mathrm{O}_{2} \rightarrow 2 \mathrm{H}_{2} \mathrm{O}+\mathrm{O}_{2}
\end{gathered}
$$

Fig. 7d shown the effect of temperature on the degradation rate of $\mathrm{TC}-\mathrm{HCl}$ by $\mathrm{Fe}_{3} \mathrm{O}_{4} / \mathrm{rGO} / \mathrm{TiO}_{2}$ nanocomposite. It is obvious that temperature has a strong effect on the degradation rate of $\mathrm{Fe}_{3} \mathrm{O}_{4} / \mathrm{rGO} / \mathrm{TiO}_{2}$ nanocomposite. The degradation rate increased with increasing temperature from $60 \%$ at $20{ }^{\circ} \mathrm{C}$ to $97 \%$ at $50{ }^{\circ} \mathrm{C}$, which may be caused by the reason that the higher temperature enhanced the reaction rate between $\mathrm{H}_{2} \mathrm{O}_{2}$ and $\mathrm{Fe}_{3} \mathrm{O}_{4} / \mathrm{rGO} / \mathrm{TiO}_{2}$ nanocomposite, thus formationing more ${ }^{\circ} \mathrm{OH}$ to take part in the reaction.

3.2.2 The possible pathway of TC-HCl degradation. The intermediates of TC-HCl were investigated by HPLC-MS and the results were illustrated in Fig. 8. The possible pathway is as follows (Fig. 9). First, the TC-HCl molecular deprotonated and the resulting molecular ion with $m / z=445$ was found. Second, the electron-hole pairs were induced on the surface of $\mathrm{Fe}_{3} \mathrm{O}_{4}$ / $\mathrm{rGO} / \mathrm{TiO}_{2}$ nanocomposite by the visible light irradiation, while the TC-HCl molecules in the solution $(\mathrm{m} / \mathrm{z}=445)$ were adsorbed onto the surface of $\mathrm{Fe}_{3} \mathrm{O}_{4} / \mathrm{rGO} / \mathrm{TiO}_{2},{ }^{40}$ and attacked by electrons or holes. In this process, various intermediates were formed as shown in Fig. 9.

3.2.3 Stability and reusability of $\mathrm{Fe}_{3} \mathrm{O}_{4} / \mathrm{rGO} / \mathrm{TiO}_{2}$ nanocomposites. The stability is one of the important factors to assess the quality of the catalysts since the photocorrosion or photodissolution might occur on the photocatalyst surface in the photocatalytic process. ${ }^{41}$ So we conducted a series of experiment to investigate the stability and reusability of the $\mathrm{Fe}_{3} \mathrm{O}_{4} / \mathrm{rGO} / \mathrm{TiO}_{2}$ nanocomposites. In the typical procedure of the stability experiment, the $\mathrm{Fe}_{3} \mathrm{O}_{4} / \mathrm{rGO} / \mathrm{TiO}_{2}$ nanocomposites was separated by centrifugation after each cycle, dried at $60{ }^{\circ} \mathrm{C}$ overnight and be used without further treatment. As apparent from Fig. 10a, the photocatalytic efficiency of $\mathrm{Fe}_{3} \mathrm{O}_{4} / \mathrm{rGO} / \mathrm{TiO}_{2}$ nanocomposites decreased slightly in the five cycles, which could be ascribed to the following two reasons: (1) the 

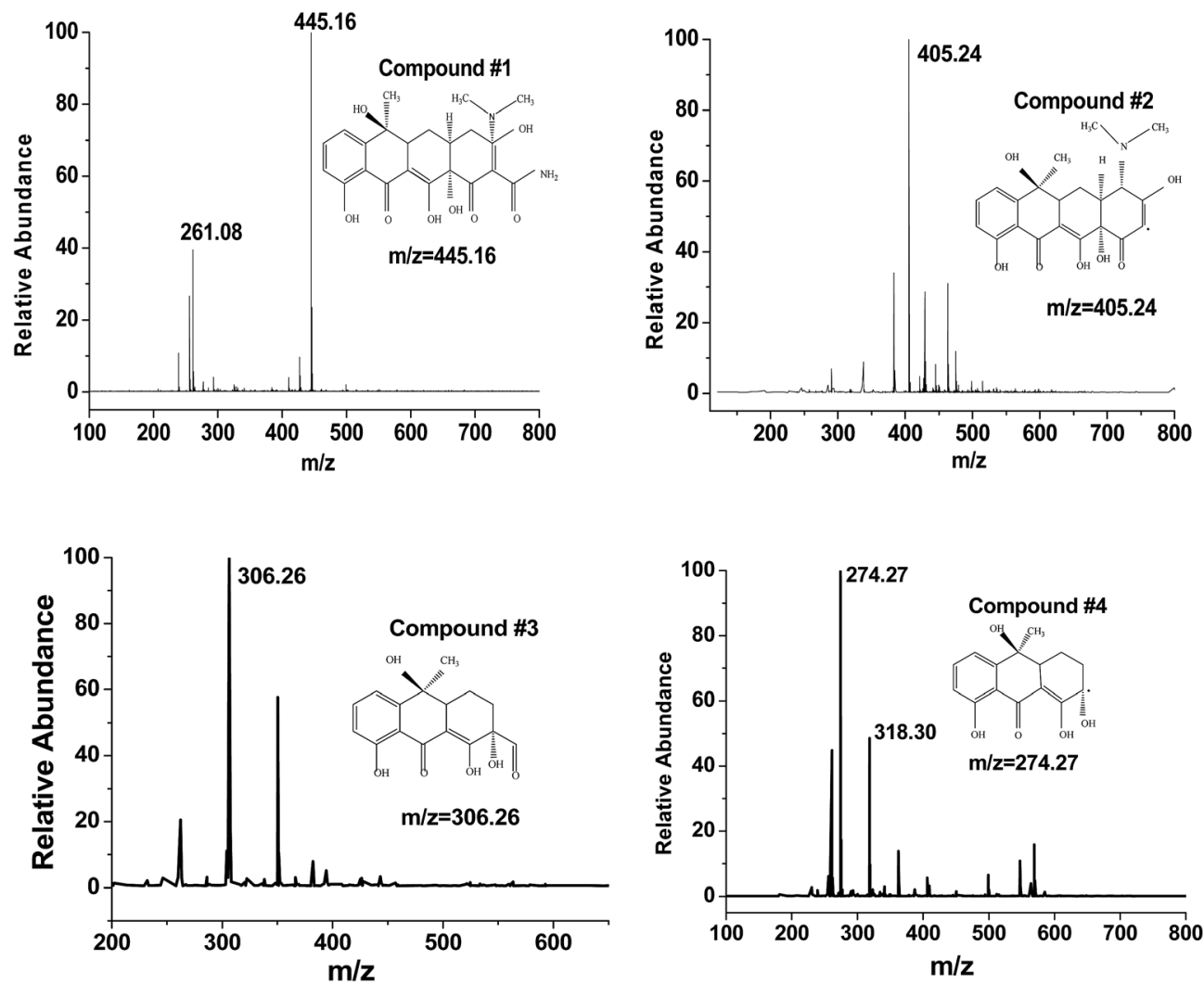

Fig. 8 Principal by-products of TC-HCl degradation detected by LC-MS

photocorrosion of the $\mathrm{Fe}_{3} \mathrm{O}_{4} / \mathrm{rGO} / \mathrm{TiO}_{2}$ nanocomposites in the reaction system; (2) the TC-HCl strongly adsorbed on the surface of the catalysts and occupy the active sites, thus reducing the photocatalytic activity. In addition, the Fe leaching in the reaction system in the first cycle is almost negligible (Fig. 10b), which can get rid of the secondary wastes that caused in the traditional Fenton process. Furthermore, the XRD and FT-IR are also utilized to test its stability. The results are presented in Fig. 11, there are almost no significant changes in the XRD pattern and FT-IR spectrum of the $\mathrm{Fe}_{3} \mathrm{O}_{4} / \mathrm{rGO} / \mathrm{TiO}_{2}$ catalyst before and after degradation, suggesting that the asprepared $\mathrm{Fe}_{3} \mathrm{O}_{4} / \mathrm{rGO} / \mathrm{TiO}_{2}$ hybrid reveals excellent stability and great potential application value.

\subsection{Possible photo-degradation mechanism of TC-HCl}

3.3.1 Quenching test. It is widely acknowledged that the active species of ${ }^{\circ} \mathrm{OH}, \mathrm{h}^{+},{ }^{\cdot} \mathrm{O}_{2}{ }^{-}, \mathrm{e}^{-}$play the main role in the photocatalytic oxidation. ${ }^{41,42}$ In order to make sure the main active species responsible for TC-HCl degradation, a series of

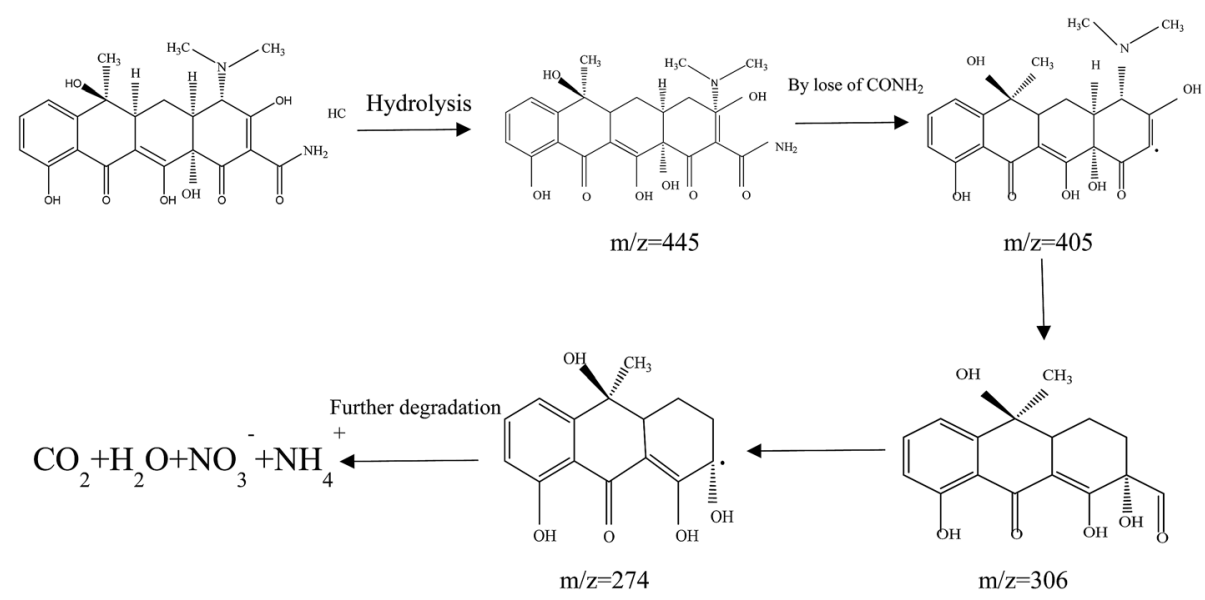

Fig. 9 Proposed TC-HCl degradation pathways in the $\mathrm{Fe}_{3} \mathrm{O}_{4} / \mathrm{rGO} / \mathrm{TiO}_{2} / \mathrm{H}_{2} \mathrm{O}_{2}$ system. 

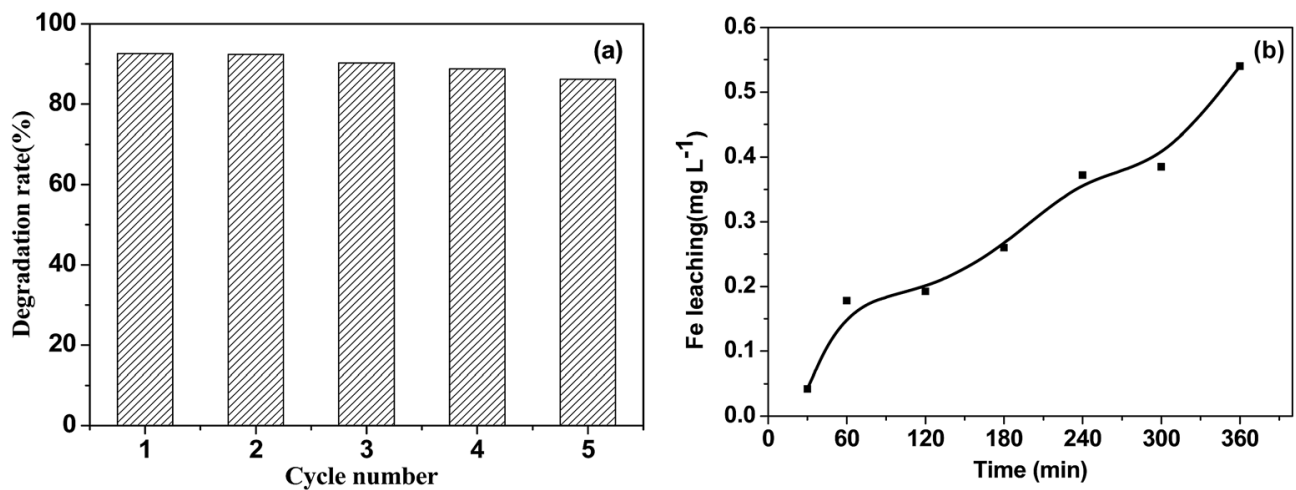

Fig. 10 (a) The stability of the $\mathrm{Fe}_{3} \mathrm{O}_{4} / \mathrm{rGO} / \mathrm{TiO}_{2}$ photocatalyst for the discoloration of $\mathrm{TC}-\mathrm{HCl}$ (b) the $\mathrm{Fe}$ leaching from $\mathrm{Fe}{ }_{3} \mathrm{O}_{4} / \mathrm{rGO} / \mathrm{TiO}{ }_{2}$ photocatalyst in the first cycle as a function of time.
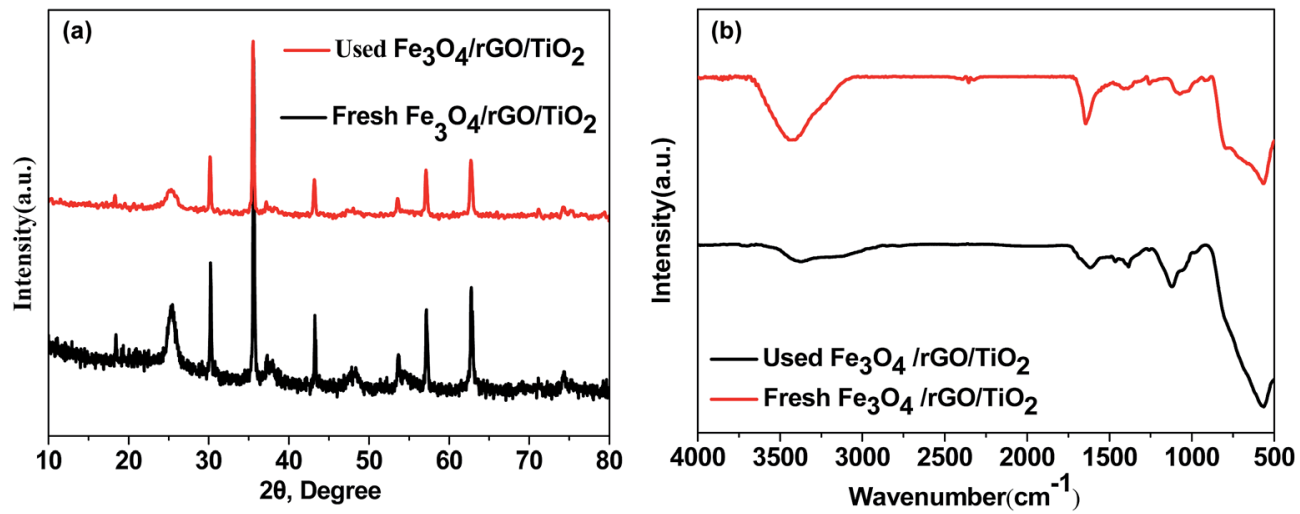

Fig. 11 (a) XRD pattern and (b) FT-IR spectra of the pristine and used $\mathrm{Fe}_{3} \mathrm{O}_{4} / \mathrm{rGO} / \mathrm{TiO}_{2}$ photocatalyst.

trapping experiments were carried out by adding some corresponding scavengers to the degradation system. Fig. 12 illustrates the results of trapping experiments over the $\mathrm{Fe}_{3} \mathrm{O}_{4} / \mathrm{rGO} /$ $\mathrm{TiO}_{2}$ photocatalyst reaction system. When $100 \mathrm{mM}$ triethanolamine (TEOA) scavenger for $\mathrm{h}^{+}$is introduced into the reaction system, the degradation rate decreased slightly by $16 \%$ (entry b in Fig. 12) compared to the pristine reaction system without radical scavengers (entry a in Fig. 12). Similarly, the degradation rate of TC-HCl is also declined by $28 \%$ (entry c in Fig. 12) when the iso-propanol (IPA), scavenger for ${ }^{\circ} \mathrm{OH}$, is added into the system. However, the photocatalytic activity of $\mathrm{Fe}_{3} \mathrm{O}_{4} / \mathrm{rGO} / \mathrm{TiO}_{2}$ is significantly inhibited when $\mathrm{BQ}$ (a quencher of ${ }^{\circ} \mathrm{O}_{2}{ }^{-}$) or DMSO (a quencher of $\mathrm{e}^{-}$) is introduced into the photocatalytic reaction system. From the above results, it can be concluded
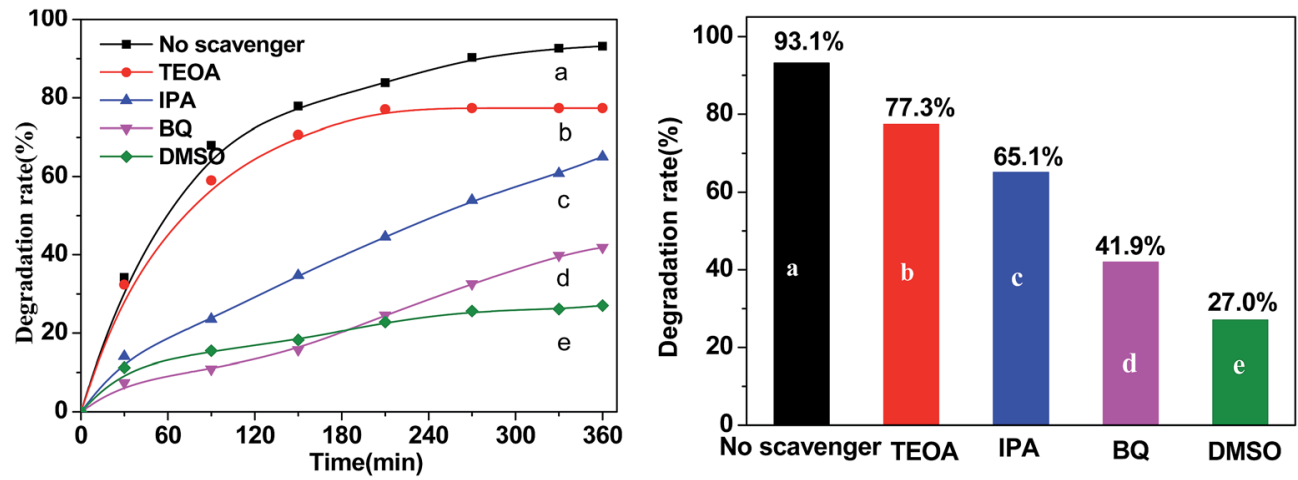

Fig. 12 Photocatalytic degradation ratios of $\mathrm{TC}-\mathrm{HCl}$ by $\mathrm{Fe}_{3} \mathrm{O}_{4} / \mathrm{rGO} / \mathrm{TiO}_{2}$ using different radical scavengers (a) reaction in the absence of radical

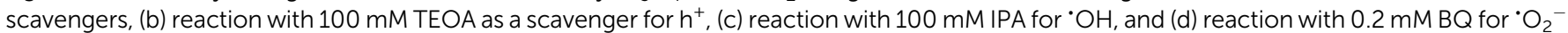
(e) reaction with $100 \mathrm{mM}$ DMSO as a scavenger for $\mathrm{e}^{-}$under visible light irradiation for $360 \mathrm{~min}$. 


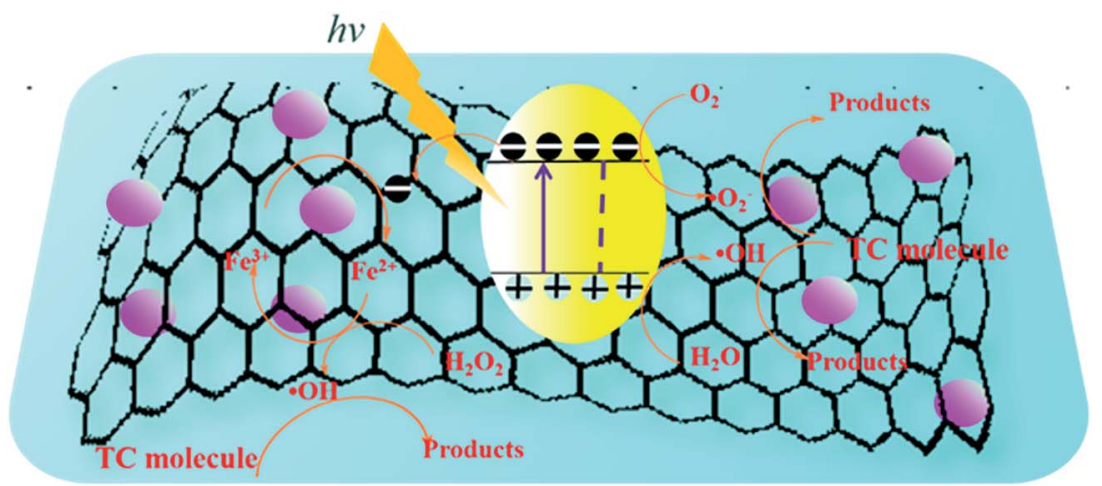

Fig. 13 Proposed schematic illustration showing the reaction mechanism for photocatalytic degradation of $\mathrm{TC}-\mathrm{HCl}$ over the $\mathrm{Fe} 3 \mathrm{O}_{4} / \mathrm{rGO} / \mathrm{TiO}{ }_{2}$ nanocomposites in which pink spheres, yellow oval and black sheet represent $\mathrm{Fe}_{3} \mathrm{O}_{4}$ nanoparticles, $\mathrm{TiO}_{2}$ nanoparticles and rGO, respectively.

that the $\mathrm{e}^{-}$radicals and ${ }^{\circ} \mathrm{O}_{2}{ }^{-}$radicals should be the two main actives species during photocatalytic degradation of TC-HCl by the $\mathrm{Fe}_{3} \mathrm{O}_{4} / \mathrm{rGO} / \mathrm{TiO}_{2}$ nanocomposites under visible light irradiation.

\subsection{Proposed mechanism of photocatalysis with the photocatalyst}

On the basis of the discussion of quenching test, the possible photocatalytic mechanism schemes of $\mathrm{Fe}_{3} \mathrm{O}_{4} / \mathrm{rGO} / \mathrm{TiO}_{2}$ is proposed, as depicted in Fig. 13. When the $\mathrm{Fe}_{3} \mathrm{O}_{4} / \mathrm{rGO} / \mathrm{TiO}_{2}$ were subjected to visible light irradiation, the excitation of an electron from the valence band to the conduction band resulting the generation of electron $\left(\mathrm{e}^{-}\right)$in the conduction band $(\mathrm{CB})$ and holes $\left(\mathrm{h}^{+}\right)$in the valence band (VB). ${ }^{43}$ For $\mathrm{Fe}_{3} \mathrm{O}_{4} / \mathrm{rGO} / \mathrm{TiO}_{2}$ system, the electron $\left(\mathrm{e}^{-}\right)$transferred to rGO sheet due to the excellent electrical conductivity of rGO, and then take part in the reduction reaction, thus inhibiting the recombination of the electron-hole pairs and making the electron transfer process more efficient. ${ }^{44}$ Besides, the rGO could also transfer the photogenerated electron to the surface of $\mathrm{Fe}_{3} \mathrm{O}_{4}$ and reduce the $\mathrm{Fe}^{3+}$ to $\mathrm{Fe}^{2+}$ because of the superior intimate contact between $\mathrm{Fe}_{3} \mathrm{O}_{4}$ and $\mathrm{rGO}^{45}$ Furthermore, the generate $\mathrm{Fe}^{2+}$ may be able to reduce the $\mathrm{H}_{2} \mathrm{O}_{2}$ to ${ }^{\circ} \mathrm{OH}$, which finally degrade organic pollutants. Of cause, it is clear from the Fig. 13 that $\mathrm{e}^{-}$in $\mathrm{CB}$ can react with $\mathrm{O}_{2}$ in the aqueous solution to produce ${ }^{\circ} \mathrm{O}_{2}{ }^{-}$to degrade the pollutant, which is in agreement with the result of trapping experiment. Meanwhile, the holes generated on the surface of $\mathrm{TiO}_{2}$ nanoparticle oxidize pollutant molecules.

\section{Conclusion}

In conclusion, $\mathrm{Fe}_{3} \mathrm{O}_{4} / \mathrm{rGO} / \mathrm{TiO}_{2}$ photocatalyst was successfully synthesized by a simple two-step process, an electrostatic selfassemble and hydrothermal method. The uniform $\mathrm{Fe}_{3} \mathrm{O}_{4}$ nanoparticles was firstly deposited on the surface of GO sheet through a facile electrostatic self-assembly method. Then the $\mathrm{TiO}_{2}$ particles was anchored on the surface of the $\mathrm{Fe}_{3} \mathrm{O}_{4} / \mathrm{rGO}$ through hydrothermal reaction. The photocatalytic activity of the as-prepared ternary catalyst $\mathrm{Fe}_{3} \mathrm{O}_{4} / \mathrm{rGO} / \mathrm{TiO}_{2}$ has been explored for the degradation of TC- $\mathrm{HCl}$. The $\mathrm{Fe}_{3} \mathrm{O}_{4} / \mathrm{rGO} / \mathrm{TiO}_{2}$ photocatalyst shows superior activity in the neutral or alkaline environment. The enhanced catalytic activity of our catalyst is due to the synergistic effect of photo-Fenton reaction and electron transportation and conducting ability as a result of deposition of graphene. The products of TC-HCl degradation were identified by LC-MS and the possible pathway and mechanism of photocatalysis of the $\mathrm{TC}-\mathrm{HCl}$ was proposed. The result reveals that the $\mathrm{e}^{-}$radicals and ${ }^{\circ} \mathrm{O}_{2}{ }^{-}$radicals should be the two main actives species during photocatalytic degradation of TC$\mathrm{HCl}$ by the $\mathrm{Fe}_{3} \mathrm{O}_{4} / \mathrm{rGO} / \mathrm{TiO}_{2}$ nanocomposites under visible light irradiation. In addition, the catalyst is reusable and shows efficiency up to 5 cycles. We believe the strategy in our work can provide insight into designing the novel photocatalysts for large-scale degradation of organic pollutants under visible light.

\section{Acknowledgements}

The authors greatly acknowledge the Foundation for Guangzhou Science and Technology Program Key Projects, China (201508020086), Guangdong Province Science and Technology Plan Project, China (2015B020230001) and the National Natural Science Foundation of China (31371743) for financial support.

\section{References}

1 Y. Chen and K. Liu, Chem. Eng. J., 2016, 302, 682-696.

2 B. Luo, D. Xu, D. Li, G. Wu, M. Wu, W. Shi and M. Chen, ACS Appl. Mater. Interfaces, 2015, 7, 17061-17069.

3 Q. Liu, L. Bin Zhong, Q. B. Zhao, C. Frear and Y. M. Zheng, ACS Appl. Mater. Interfaces, 2015, 7, 14573-14583.

4 H. Li, D. Zhang, X. Han and B. Xing, Chemosphere, 2014, 95, 150-155.

5 S. K. Bajpai and M. Bhowmik, J. Macromol. Sci., Part A: Pure Appl. Chem., 2011, 48, 108-118.

6 R. Levine, Civil Engineering Theses, Dissertations, and Student Research, 2016.

7 F. Chen, Q. Yang, X. Li, G. Zeng, D. Wang, C. Niu, J. Zhao, H. An, T. Xie and Y. Deng, Appl. Catal., B, 2017, 200, 330-342.

8 M. Haidar, A. Dirany, I. Sirés, N. Oturan and M. A. Oturan, Chemosphere, 2013, 91, 1304-1309. 
9 S. zhong Li, X. yan Li and D. zuo Wang, Sep. Purif. Technol., 2004, 34, 109-114.

10 H. Hou, F. Gao, L. Wang, M. Shang, Z. Yang, J. Zheng and weiyou yang, J. Mater. Chem. A, 2016, 4, 6276-6281.

11 M. Xing, X. Li and J. Zhang, Sci. Rep., 2014, 4, 5493.

12 W. T. Sun, A. Yu, H. Y. Pan, X. F. Gao, Q. Chen and L. M. Peng, J. Am. Chem. Soc., 2008, 130, 1124-1125.

13 S. Rawalekar and T. Mokari, Adv. Energy Mater., 2013, 3, 1227.

14 M. Ni, M. K. H. Leung, D. Y. C. Leung and K. Sumathy, Renewable Sustainable Energy Rev., 2007, 11, 401-425.

15 X. Zong, H. Yan, G. Wu, G. Ma, F. Wen, L. Wang and C. Li, J. Am. Chem. Soc., 2008, 130, 7176-7177.

16 A. Fujishima, X. Zhang and D. A. Tryk, Surf. Sci. Rep., 2008, 63, 515-582.

17 R. Daghrir, P. Drogui and D. Robert, Ind. Eng. Chem. Res., 2013, 52, 3581-3599.

18 J. Deng, X. Wen and Q. Wang, Mater. Res. Bull., 2012, 47, 3369-3376.

19 N. Zhang, Y. Zhang and Y.-J. Xu, Nanoscale, 2012, 4, 5792.

20 H. Deng, X. Li, Q. Peng, X. Wang, J. Chen and Y. Li, Angew. Chem., Int. Ed., 2005, 44, 2782-2785.

21 Y. Zhang, Z. Tang, X Fu and Y. Xu, ACS nano, 2010, 4, 73037314.

22 M. Zhao, L. Figueroa-Cosme, A. O. Elnabawy, M. Vara, X. Yang, L. T. Roling, M. Chi, M. Mavrikakis and Y. Xia, Nano Lett., 2016, 16, 5310-5317.

23 R. K. Das, J. P. Kar and S. Mohapatra, Ind. Eng. Chem. Res., 2016, 55, 5902-5910.

24 G. Fu, L. Ding, Y. Chen, J. Lin, Y. Tang and T. Lu, CrystEngComm, 2014, 16, 1606-1610.

25 A. A. Al-Kahtani and M. F. Abou Taleb, J. Hazard. Mater., 2016, 309, 10-19.

26 T. Xin, M. Ma, H. Zhang, J. Gu, S. Wang, M. Liu and Q. Zhang, Appl. Surf. Sci., 2014, 288, 51-59.

27 W. Li, J. Yang, Z. Wu, J. Wang, B. Li, S. Feng, Y. Deng, F. Zhang and D. Zhao, J. Am. Chem. Soc., 2012, 134, 1186411867.
28 L. Tan, X. Zhang, Q. Liu, X. Jing, J. Liu, D. Song, S. Hu, L. Liu and J. Wang, Colloids Surf., A, 2015, 469, 279-286.

29 G. Mishra, K. M. Parida and S. K. Singh, ACS Sustainable Chem. Eng., 2015, 3, 245-253.

30 A. Tayyebi, M. Outokesh, S. Moradi and A. Doram, Appl. Surf. Sci., 2015, 353, 350-362.

31 M. Wang, J. Han, H. Xiong and R. Guo, Langmuir, 2015, 31, 6220-6228.

32 R. Ren, Z. Wen, S. Cui, Y. Hou, X. Guo and J. Chen, Sci. Rep., 2015, 5, 10714.

33 D. R. Tobergte and S. Curtis, J. Chem. Inf. Model., 2013, 53, 1689-1699.

34 G. T. S. How, A. Pandikumar, H. N. Ming and L. H. Ngee, Sci. Rep., 2014, 4, 5044.

35 Z. Xu, C. Huang, L. Wang, X. Pan, L. Qin, X. Guo and G. Zhang, Ind. Eng. Chem. Res., 2015, 54, 4593-4602.

36 W. Zhang, X. Li, R. Zou, H. Wu, H. Shi, S. Yu and Y. Liu, Sci. Rep., 2015, 5, 11129.

37 P. H. Chang, Z. Li, J. S. Jean, W. T. Jiang, C. J. Wang and K. H. Lin, Appl. Clay Sci., 2012, 67-68, 158-163.

38 Y. Ma, N. Gao and C. Li, Environ. Eng. Sci., 2012, 29, 357362.

39 L. Hu, D. Xu, L. Zou, H. Yuan and X. Hu, Acta Phys.-Chim. Sin., 2015, 31, 771-782.

40 K. Dai, T. Peng, H. Chen, J. Liu and L. Zan, Environ. Sci. Technol., 2009, 43, 1540-1545.

41 M. Zhou, D. Han, X. Liu, C. Ma, H. Wang, Y. Tang, P. Huo, W. Shi, Y. Yan and J. Yang, Appl. Catal., B, 2015, 172-173, 174-184.

42 G. Zhang, W. Guan, H. Shen, X. Zhang, W. Fan, C. Lu, H. Bai, L. Xiao, W. Gu and W. Shi, Ind. Eng. Chem. Res., 2014, 53, 5443-5450.

43 A. L. Linsebigler, A. L. Linsebigler, J. T. Yates Jr, G. Lu, G. Lu and J. T. Yates, Chem. Rev., 1995, 95, 735-758.

44 S. Zhong, W. Jiang, M. Han, G. Liu, N. Zhang and Y. Lu, Appl. Surf. Sci., 2015, 347, 242-249.

45 Y. Park, S.-H. Kang and W. Choi, Phys. Chem. Chem. Phys., 2011, 13, 9425-9431. 